\title{
DISTRIBUTION PATTERNS AND RISK FACTORS OF DYSLIPIDEMIA IN PATIENTS WITH TYPE 2 DIABETES MELLITUS: A CROSS-SECTIONAL STUDY IN BOGOR, INDONESIA
}

\author{
SARASWATI PRADIPTA ${ }^{1}$, HERI WIBOWO $1,2 *$, DANTE SAKSONO HARBUWONO ${ }^{3}$, EKOWATI RAHAJENG ${ }^{4}$, \\ RAHMA AYU LARASATI ${ }^{1}$, RONA KARTIKA ${ }^{1}$
}

${ }^{1}$ Magister Program of Biomedical Science, Faculty of Medicine, Universitas Indonesia, Jakarta 10440, Indonesia. ${ }^{2}$ Department of Parasitology, Faculty of Medicine, Universitas Indonesia, Jakarta 10440, Indonesia. ${ }^{3}$ Department of Internal Medicine, Faculty of Medicine, Universitas Indonesia, Jakarta 10440, Indonesia. ${ }^{4}$ Centre for Research and Development of Public Health, National Institute of Health Research and Development, Ministry of Health, Jakarta 12950, Indonesia. Email: bowoheri04@gmail.com

Received: 29 October 2019, Revised and Accepted: 04 February 2020

ABSTRACT

Objective: Type 2 diabetes mellitus (T2DM) patients tend to have abnormal lipid profiles, explaining the association between elevated cholesterol and triglyceride levels in diabetic patients and coronary heart disease. This study aims to evaluate how the common risk factors for dyslipidemia affect the lipid profile of diabetic patients and to determine which factors can be used as predictors for the occurrence of dyslipidemia in T2DM patients.

Methods: A total of 238 diabetic patients (63 male and 175 female; age: 31-70 years) were enrolled in this cross-sectional study. All of them had undergone regular examinations in cohort studies on risk factors for non-communicable diseases conducted by the Ministry of Health in Bogor between December 2017 and January 2018.

Results: The result found that age differences did not affect lipid profile levels, and the females had higher mean values of body mass index (p $<0.001$ ), total cholesterol (TC) $(\mathrm{p}<0.05)$, and high-density lipoprotein (HDL) $(\mathrm{p}<0.001)$ than the males. The most common occurrences of dyslipidemia were high TC level (57.1\%), followed by high low-density lipoprotein (LDL) level (47.1\%), high triglyceride level (37.4\%), and low HDL level (16.4\%). Being overweight was found to be the best predictor of dyslipidemia.

Conclusion: The results of this study suggest that in T2DM patients, sex affects TC and HDL levels, whereas age does not exert a significant effect on the lipid profiles. In addition, poor glycemic control, hypertension, and obesity may serve as predictors of dyslipidemia in T2DM patients.

Keywords: Type 2 diabetes, Dyslipidemia, Cardiovascular disease.

(C) 2020 The Authors. Published by Innovare Academic Sciences Pvt Ltd. This is an open access article under the CC BY license (http://creativecommons. org/licenses/by/4. 0/) DOI: http://dx.doi.org/10.22159/ijap.2020.v12s1.24045

\section{INTRODUCTION}

Diabetes has become a global concern due to its increasing incidence. The number of patients with diabetics is expected to increase from 425 million in 2017 to 693 million by 2045. The leading cause of morbidity and mortality for patients with type 2 diabetes mellitus (T2DM) is cardiovascular diseases (CVDs) [1]. T2DM is associated with an increased risk of macrovascular diseases such as atherosclerosis, coronary heart disease, and peripheral arterial disease [2]. Independently, diabetes may bring about a two-fold increase in the risk of macrovascular disease [3] as well as increase the effects of other risk factors that cause macrovascular diseases such as smoking, hypertension, and hypercholesterolemia [4]. The mortality rate associated with vascular abnormalities in people with diabetes mellitus is significantly higher than that of nondiabetic individuals [5]. According to the American Heart Association, at least $68 \%$ of the people with diabetes aged $>65$ years die of heart disease, whereas $16 \%$ die of stroke [6]. The overall cardiometabolic risk of diabetes is driven by a complex interplay between several non-modifiable (age, sex, and genetics) and modifiable (hypertension, hyperlipidemia, and hyperglycemia) factors and the components of the metabolic syndrome commonly associated with type 2 diabetes [1]. Therefore, patients with T2DM tend to have abnormal lipid profiles, which include increased total cholesterol (TC), increased cholesterol low-density lipoprotein (LDL), increased triglyceride (TG), and decreased cholesterol high-density lipoprotein (HDL) [7]. This explains the association between coronary heart disease and elevated cholesterol and triglyceride levels observed in patients with diabetes $[2,8]$. The impairment of sugar metabolism that occurs in patients with T2DM is strongly associated with impaired fat metabolism.
Several known factors that contribute to this include insulin deficiency or resistance, adipocytokines, and hyperglycemia [9].

Indonesia has a high prevalence of diabetes. In 2015 , it was the $7^{\text {th }}$ country with the highest T2DM prevalence in the world with a $6 \%$ prevalence rate of diabetes-associated deaths. Although dyslipidemia plays an underlying role in diabetes, how its incidence is influenced by other risk factors is not widely known. Rather, unique genetic, cultural, and environmental factors shape the geographic patterns [10]. According to the $\mathrm{WHO}$, the overall prevalence of dyslipidemia in Indonesia in 25-year-old adults

Table 1: Extraction parameters

\begin{tabular}{llll}
\hline Variables & Sex & p \\
\cline { 2 - 3 } & $\begin{array}{l}\text { Male (n=63) } \\
\text { Mean } \pm \text { SD }\end{array}$ & $\begin{array}{l}\text { Female(n=175) } \\
\text { Mean } \pm \text { SD }\end{array}$ & \\
\hline Age & $53.56 \pm 9.11$ & $52.85 \pm 9.15$ & 0.527 \\
Body weight (kg) & $66.90 \pm 11.05$ & $63.28 \pm 12.40$ & $0.022^{*}$ \\
Body mass index & $25.56 \pm 4.12$ & $28.07 \pm 4.77$ & $0.000^{*}$ \\
Fasting plasma & $142.08 \pm 55.56$ & $152.76 \pm 81.81$ & 0.718 \\
glucose (mg/dL) & & & \\
2-h plasma glucose & $207.12 \pm 105.80$ & $228.28 \pm 103.23$ & 0.061 \\
(mg/dL) & & & \\
HbA1c (\%) & $7.20 \pm 2.33$ & $6.80 \pm 2.40$ & 0.055 \\
$\begin{array}{l}\text { Systole (mmHg) } \\
\text { Diastole (mmHg) }\end{array}$ & $141.61 \pm 23.48$ & $139.29 \pm 21.62$ & 0.479 \\
\hline *p<0.05 & $88.68 \pm 11.91$ & $88.12 \pm 12.94$ & 0.734 \\
\hline
\end{tabular}


Table 2: Lipid profile in different age group

\begin{tabular}{|c|c|c|c|c|c|}
\hline \multirow{2}{*}{$\begin{array}{l}\text { Lipid } \\
\text { profiles }\end{array}$} & \multicolumn{4}{|l|}{ Age } & \multirow[t]{2}{*}{$\mathbf{p}$} \\
\hline & $30-39(n=19)$ Mean $\pm S D$ & $40-49(n=68)$ Mean $\pm S D$ & $50-59(n=90)$ Mean $\pm S D$ & $\geq 60(n=61)$ Mean \pm SD & \\
\hline TC & $196.91 \pm 36.83$ & $206.68 \pm 36.63$ & $213.82 \pm 40.38$ & $208.03 \pm 45.43$ & 0.317 \\
\hline TG & $132.63 \pm 65.21$ & $132.62 \pm 65.00$ & $152.86 \pm 74.51$ & $160.43 \pm 117.06$ & 0.278 \\
\hline LDL & $125.13 \pm 26.17$ & $129.59 \pm 30.91$ & $132.82 \pm 31.51$ & $128.48 \pm 39.21$ & 0.671 \\
\hline HDL & $48.38 \pm 6.68$ & $51.05 \pm 12.47$ & $50.02 \pm 12.21$ & $50.99 \pm 12.61$ & 0.940 \\
\hline
\end{tabular}

Table 3: Lipid profile in different sex

\begin{tabular}{llll}
\hline Lipid profiles & Sex & p \\
\cline { 2 - 3 } & Male & Female & \\
\hline TC & $201.93 \pm 39.80$ & $211.47 \pm 40.55$ & $0.039^{*}$ \\
TG & $166.87 \pm 115.48$ & $140.39 \pm 69.83$ & 0.232 \\
LDL & $124.79 \pm 31.02$ & $132.11 \pm 33.57$ & 0.059 \\
HDL & $44.53 \pm 11.29$ & $52.56 \pm 11.56$ & $0.000^{*}$ \\
\hline
\end{tabular}

${ }^{*} \mathrm{p}<0.05$. TC: Total cholesterol, TG: Triglyceride, LDL: Low-density lipoprotein, HDL: High-density lipoprotein

is around $35.8 \%$ [11]. It is against this background that this study was conducted to examine how the common risk factors for dyslipidemia affect the lipid profile of patients with diabetes and determine which of these factors can serve as the best predictors of its occurrence in T2DM.

\section{MATERIALS AND METHODS}

This study is a cross-sectional study. We analyzed the database of cohort studies on risk factors for non-communicable diseases carried out by the Ministry of Health in Bogor. This study was approved by the Ethical Committee of the Faculty of Medicine, Universitas Indonesia, and informed consent was obtained from each participant. We collected data on 238 diabetes subjects (31-70 years old) who had received regular examinations in the Ministry of Health cohort study. The data were obtained between December 2017 and January 2018. The diagnosis of diabetes was based on the criteria of the American Diabetes Association as follows: Glycosylated hemoglobin (HbA1c) level $\geq 6.5 \%$, or a fasting plasma glucose (FPG) level $\geq 126 \mathrm{mg} / \mathrm{dL}$, or a 2 -h plasma glucose level $\geq 200 \mathrm{mg} / \mathrm{dL}$ during a 75 -g oral glucose tolerance test (OGTT), or a random plasma glucose $\geq 200 \mathrm{mg} / \mathrm{dL}$ in patients with classic symptoms of hyperglycemia (i.e., polyuria, polydipsia, polyphagia, and weight loss) or hyperglycemic crisis. Dyslipidemia was defined as a TC level $\geq 200 \mathrm{mg} /$ $\mathrm{dL}$, or a triglyceride level $\geq 150 \mathrm{mg} / \mathrm{dL}$, or a low-density lipoprotein cholesterol (LDL-C) $\geq 130 \mathrm{mg} / \mathrm{dL}$, or a high-density lipoprotein cholesterol (HDL-C) $\leq 40 \mathrm{mg} / \mathrm{dL}$. Poor glycemic control was defined as HbA1c $>7 \%$. Hypertension was defined as taking antihypertensive medications or having a systolic blood pressure (BP) of $\geq 140 \mathrm{mmHg}$ and/or a diastolic $\mathrm{BP}$ of $\geq 90 \mathrm{mmHg}$. Overweight was defined as body mass index (BMI) $\geq 25$.

We compared the mean lipid profile data based on sex and the age groups $30-39,40-49,50-59$, and $\geq 60$. The mean significance test for the age groups was done by ANOVA for normally distributed data and the Kruskal-Wallis test for data that are not normally distributed. The t-test was used to evaluate the sex group for normally distributed data and the Mann-Whitney test for data that are not normally distributed. We calculated the odds ratios (ORs) for poor glycemic control, hypertension, and overweight by dyslipidemia on each lipid profile (high TC, high TG, high LDL-C, and low HDL-C). Differences with a $\mathrm{p}<0.05$ were considered statistically significant. All statistical analyses were performed using the SPSS Statistics software (IBM SPSS Statistics version 24 for Windows; IBM, New York, NY, USA).

\section{RESULTS AND DISCUSSION}

\section{Subject characteristics}

The characteristics of the 238 subjects were divided into male and female sex groups as shown in Table 1 . There were no significant differences in the characteristics in terms of age, FPG, 2-h PG, HbA1c, and the systolic and diastolic BPs between the male and female groups. However, significant differences were seen in the body weight and BMI, the latter being higher in the females. Although both were significantly different, the BMI levels in both groups fall into the overweight category.

Lipid profile characteristic based on age and sex

The lipid profiles were stratified in terms of age group and sex. The results in Table 2 showed that there were no statistically significant lipid level differences within each age group. In terms of sex, there were statistically significant differences in TC and HDL level (Table 3). The mean TC in the female group was higher than the male group $(\mathrm{p}=0.039)$ while the mean HDL in the female group was also higher compared to the male group $(\mathrm{p}=0.000)$.

\section{Pattern of dyslipidemia in study subjects}

The prevalence of dyslipidemia in terms of TC, TG, LDL, and HDL showed that the most elevated indices of dyslipidemia were high TC levels (57.1\%), followed by high LDL levels (47.1\%), high TG levels (37.4\%), and low HDL levels (16.4\%). In terms of the pattern of dyslipidemia, subjects with two types of lipid abnormalities were the highest (35.3\%), followed by three types of abnormalities (21.0\%), one type of abnormality (26.9), and all four types of abnormalities (2.5\%). The number of subjects who did not have lipid abnormalities was $64(26.9 \%)$

\section{Dyslipidemia risk factor}

Table 4 showed that being overweight increased the risk of dyslipidemia in the form of abnormalities in the level of TC, TG, and LDL. In addition, being hypertensive increased the risk of abnormalities in the level of TC and LDL. The least predictor of dyslipidemia was poor glycemic control, which increased the risk of abnormalities only in the level of TG.

\section{DISCUSSION}

An examination of the biomedical parameters of the diabetes subjects in this study showed that there were no statistical differences in the glycemic characteristics of FPG, OGTT, and HbA1c between the male and female groups. In line with the results of this study, studies in Turkey, in patients at a high risk for diabetes in the US, and in cynomolgus monkeys with impaired FPG, indicate that sex is not associated with FPG level [12-14]. Another study on diabetic and nondiabetic subjects showed significant differences in FPG level between males and females [15]. In this study, significant differences $(p \leq 0.001)$ between males and females were observed in the BMI, though the BMI values were higher in the females. This is consistent with the idea that females generally tend to be more obese compared to males [16]. Several studies support this idea, noting that females with diabetes have a higher BMI compared to males with diabetes. On the other hand, the male muscles generally have less fat compared to the female muscles [17].

There are significant differences in TC and HDL. Females with diabetes tend to have a higher TC than males but females also have higher HDL values. However, HDL has cardioprotective properties compared to other fats [18]. The TC mean values in the females observed in this study were higher than that of males, this finding consistent with other research studies that stated women who have impaired glucose tolerance and diabetes mellitus have a higher relative risk of dying due to CVD compared to males with diabetes [19]. 
Table 4: Odds ratio for lipid parameters

\begin{tabular}{|c|c|c|c|c|}
\hline \multirow[t]{2}{*}{ Variables } & TC & TG & LDL & HDL \\
\hline & OR (CI) & OR (CI) & OR (CI) & OR (CI) \\
\hline HbA1c $>7$ & $1.329(0.762-2.320)$ & $2.176^{*}(1.245-3.805)$ & $1.389(0.804-2.399)$ & $0.938(0.446-1.969)$ \\
\hline Hypertension & $2.666^{*}(1.571-4.523)$ & $0.799(0.472-1.352)$ & $2.400 *(1.422-4.050)$ & $0.638(0.319-1.274)$ \\
\hline Overweight & $2.280 *(1.292-4.022)$ & $2.115^{*}(1.141-3.920)$ & $1.775^{*}(1.002-3.143)$ & $0.470(0.232-0.952)$ \\
\hline
\end{tabular}

TC: Total cholesterol, TG: Triglyceride, LDL: Low-density lipoprotein, HDL: High-density lipoprotein, OR: Odd ratios, CI: Confidence interval

Levels of lipid profiles based on age group indicate that age does not affect the lipid profile of patients with diabetes. Research on other patients with diabetes showed that the relationship between the age of diabetic subjects with elevated TC, HDL, and LDL values significantly had a negative correlation with a very low correlation coefficient [20]. Another study in elderly subjects showed that HDL level is not correlated with age [21].

The most common pattern of dyslipidemia among the subjects in this study was combined dyslipidemia. Patients with diabetes tend to have high triglycerides, an abnormal blood lipid profile consisting of slightly elevated low-density lipoprotein cholesterol (LDL-C), and moderately decreased high-density lipoprotein cholesterol (HDL-C) [7]. The condition is called atherogenic dyslipidemia and is commonly found in patients with obesity, metabolic syndrome, insulin resistance, and T2DM. It is also an important marker of increased CVD risk [22].

The numbers of patients with diabetes with HDL $\leq 40 \mathrm{mg} / \mathrm{dL}$ were not as much as other lipid abnormalities. In the atherogenesis process, LDL has the most important role while HDL works to reduce the risk. HDL serves to facilitate the excess of cholesterol efflux from cells in the periphery and turning back the cholesterol to the liver for excretion into bile. HDL may also bring enzymes that further can reduce oxidized lipids [23]. Thus, inadequate levels of HDL-C are related to more atherogenic forms of LDL and it commonly seen in T2DM, foil the natural homeostatic process, and contribute to atherogenesis [23]. HDL mean levels in this study bat various age levels or different sex were above the standard level $(40 \mathrm{mg} / \mathrm{dL})$. Therefore, it may be considered that the subjects in this study have some protection against the formation of atherogenic dyslipidemia.

The OR shows that being overweight is the best predictor of the incidence of dyslipidemia in diabetes because it can significantly increase the risk of abnormalities in TC by 2280 times, TG by 2115 times, and LDL by 1,775 times compared to the values in normalweight people. Based on data from the WHO in 2016, the prevalence of overweight in Indonesia was $24.4 \%$ (male $20.7 \%$ and female 28.1) [24]. The prevalence of overweight in female was higher than males, which is consistent with the results of this study. The selection of overweight as a limitation of BMI in this study is based on the high prevalence of overweight in Indonesia compared to the prevalence of obesity (5.7\%). Overweight and obesity are one of the main causes of metabolic syndrome that includes insulin resistance, T2DM, and dyslipidemia, all of which are also risk factor for CVD [25]. Another study suggests that overweight school children were 2.4-7.1 times more likely to have elevated TC, LDL cholesterol, and TG compared to normal weight school children [26]. Moreover, overweight adolescents who remained overweight in adulthood were $2.4,3$, and 8 times more likely to have abnormal LDL cholesterol, TG, and HDL cholesterol concentrations than those who remain lean [27].

Hypertension can increase the risk of TC abnormalities by 2.666 and LDL by 2.400 times higher than in subjects with normal BP. Research on working-age Japanese males showed that there is a link between hypertension and increased levels of TC, LDL, and non-HDL [28]. Another study conducted in Bangladesh using T2DM patients showed a link between hypertension and an increased risk of abnormal TC levels by 1.50 and HDL by 1.67 times higher [29]. Poor glycemic control can increase the risk of abnormalities 2.176 times higher than in subjects with good glycemic control. Glycemic control can be used as a predictor of the incidence of dyslipidemia [29].

The major limitation of the present study is that the data used were restricted to the Bogor area only. As such, it cannot represent the overall Indonesian situation. With Indonesia being the biggest archipelago country with various tribes and cultural customs, follow-up research studies that utilize larger data are needed to establish the prevalence rate in the whole of Indonesia.

\section{CONCLUSION}

Based on the results of this study, we can conclude that in T2DM patients, sex affects the TC and HDL level, whereas age grouping did not show significant differences in any lipid profiles. Poor glycemic control, hypertension, and overweight may serve as predictors of dyslipidemia in T2DM.

\section{ACKNOWLEDGMENTS}

This study was funded PITTA Grants by Universitas Indonesia with the data obtained from Directory General of Non-Communicable Disease, Indonesian Ministry of Health.

\section{CONFLICTS OF INTEREST}

The author has no conflicts of interest to declare.

\section{REFERENCES}

1. Dake AW, Sora ND. Diabetic dyslipidemia review: An update on current concepts and management guidelines of diabetic dyslipidemia. Am J Med Sci 2016;351:361-5.

2. Schofield JD, Liu Y, Rao-Balakrishna P, Malik RA, Soran H. Diabetes dyslipidemia. Diabetes Ther 2016;7:203-19.

3. Emerging Risk Factors Collaboration, Sarwar N, Gao P, Seshasai SR, Gobin R, Kaptoge S, et al. Diabetes mellitus, fasting blood glucose concentration, and risk of vascular disease: A collaborative metaanalysis of 102 prospective studies. Lancet 2010;375:2215-22.

4. Mooradian AD. Dyslipidemia in Type 2 diabetes mellitus. Nat Clin Pract Endocrinol Metab 2009;5:150-9.

5. Almdal T, Scharling H, Jensen JS, Vestergaard H. The independent effect of Type 2 diabetes mellitus on ischemic heart disease, stroke, and death: A population-based study of 13,000 men and women with 20 years of follow-up. Arch Intern Med 2004;164:1422-6.

6. Powers WJ, Rabinstein AA, Ackerson T, Adeoye OM, Bambakidis NC, Becker K, et al. 2018 Guidelines for the early management of patients with acute ischemic stroke: A guideline for healthcare professionals from the American heart association/American stroke association. Stroke 2018;49:e46-e110.

7. Windler E. What is the consequence of an abnormal lipid profile in patients with Type 2 diabetes or the metabolic syndrome? Atheroscler Suppl 2005;6:11-4.

8. Howard BV, Robbins DC, Sievers ML, Lee ET, Rhoades D, Devereux RB, et al. LDL cholesterol as a strong predictor of coronary heart disease in diabetic individuals with insulin resistance and low LDL: The strong heart study. Arterioscler Thromb Vasc Biol 2000;20:830-5.

9. Taskinen MR. Diabetic dyslipidaemia: From basic research to clinical practice. Diabetologia 2003;46:733-49.

10. Lin CF, Chang YH, Chien SC, Lin YH, Yeh HY. Epidemiology of dyslipidemia in the Asia Pacific region. Int J Gerontol 2018;12:2-6.

11. GHO by Category Raised Total Cholesterol ( $\geq 5.0 \mathrm{mmol} / \mathrm{L})$ Data by Country. World Health Organization. Available from: http://www.apps. 
who.int/gho/data/view.main.2467?lang=en.

12. Yue F, Zhang G, Tang R, Zhang Z, Teng L, Zhang Z. Age- and sexrelated changes in fasting plasma glucose and lipoprotein in cynomolgus monkeys. Lipids Health Dis 2016;15:111.

13. Bozkaya G, Ozgu E, Karaca B. The association between estimated average glucose levels and fasting plasma glucose levels. Clinics (Sao Paulo) 2010;65:1077-80.

14. Perreault L, Ma Y, Dagogo-Jack S, Horton E, Marrero D, Crandall J, et al. Sex differences in diabetes risk and the effect of intensive lifestyle modification in the diabetes prevention program. Diabetes Care 2008;31:1416-21.

15. Chung JK, Xue H, Pang EW, Tam DC. Accuracy of fasting plasma glucose and hemoglobin A1c testing for the early detection of diabetes: A pilot study. Front Lab Med 2017;1:76-81

16. Ng M, Fleming T, Robinson M, Thomson B, Graetz N, Margono C, et al. Global, regional, and national prevalence of overweight and obesity in children and adults during 1980-2013: A systematic analysis for the global burden of disease study 2013. Lancet 2014;384:766-81.

17. Kautzky-Willer A, Harreiter J, Pacini G. Sex and gender differences in risk, pathophysiology and complications of Type 2 diabetes mellitus. Endocr Rev 2016;37:278-316.

18. LDL and HDL: Good and Bad Cholesterol. Available from: https:// www.cdc.gov/cholesterol/ldl hdl.htm.

19. Hu G, DECODE Study Group. Gender difference in all-cause and cardiovascular mortality related to hyperglycaemia and newlydiagnosed diabetes. Diabetologia 2003;46:608-17.

20. Khan HA, Sobki SH, Khan SA. Association between glycaemic control and serum lipids profile in Type 2 diabetic patients: HbA1c predicts dyslipidaemia. Clin Exp Med 2007;7:24-9.

21. Weijenberg MP, Feskens EJ, Kromhout D. Age-related changes in total and high-density-lipoprotein cholesterol in elderly Dutch men. Am J
Public Health 1996;86:798-803.

22. Musunuru K. Atherogenic dyslipidemia: Cardiovascular risk and dietary intervention. Lipids 2010;45:907-14.

23. Bandeali S, Farmer J. High-density lipoprotein and atherosclerosis: The role of antioxidant activity. Curr Atheroscler Rep 2012;14:101-7.

24. World Health Organization. Diabetes Country Profiles. Geneva: World Health Organization; 2016. Available from: http://www.who.int/ diabetes/country-profiles/en.

25. D'Adamo E, Guardamagna O, Chiarelli F, Bartuli A, Liccardo D, Ferrari $\mathrm{F}$, et al. Atherogenic dyslipidemia and cardiovascular risk factors in obese children. Int J Endocrinol 2015;2015:912047.

26. Steinberger J, Daniels SR, American Heart Association Atherosclerosis, Hypertension, and Obesity in the Young Committee (Council on Cardiovascular Disease in the Young), American Heart Association Diabetes Committee (Council on Nutrition, Physical Activity, and Metabolism). Obesity, insulin resistance, diabetes, and cardiovascular risk in children: An American heart association scientific statement from the atherosclerosis, hypertension, and obesity in the young committee (council on cardiovascular disease in the young) and the diabetes committee (council on nutrition, physical activity, and metabolism). Circulation 2003;107:1448-53.

27. Srinivasan SR, Bao W, Wattigney WA, Berenson GS. Adolescent overweight is associated with adult overweight and related multiple cardiovascular risk factors: The Bogalusa heart study. Metabolism 1996;45:235-40.

28. Otsuka T, Takada H, Nishiyama Y, Kodani E, Saiki Y, Kato K, et al. Dyslipidemia and the risk of developing hypertension in a working-age male population. J Am Heart Assoc 2016;5:e003053.

29. Karim MN, Ahmed KR, Bukht MS, Akter J, Chowdhury HA, Hossain S, et al. Pattern and predictors of dyslipidemia in patients with Type 2 diabetes mellitus. Diabetes Metab Syndr 2013;7:95-100. 